\title{
Estigma e preconceito na atualidade: vivência dos portadores de tuberculose em oficinas de terapia ocupacional
}

\section{I ${ }^{1}$ Thauana dos Santos Fernandes, ${ }^{2}$ Noelle da Silva Pedrosa, ${ }^{3}$ Marcia Karolyne de Quadros Garcia, ${ }^{4}$ Angela Maria Bittencourt Fernandes da Silva I}

Resumo: Objetivo: Avaliar qualitativamente o estigma e o preconceito vividos pelos portadores de tuberculose em seu contexto socioafetivo profissional, suas relaçóes e subjetividades. Método: Estudo avaliativo-qualitativo, desenvolvido por meio da Avaliação de Quarta Geração, realizado com dois grupos de interesse (18 clientes e 11 familiares) atendidos pelo Sistema Único de Saúde da Zona Oeste do Rio de Janeiro. Para a coleta de dados, utilizaramse a observação, a entrevista individual e os grupos de acolhimento da terapia ocupacional; a análise ocorreu pelo método hermenêutico-dialético-comparativo. Resultados: O processo avaliativo evidenciou que a sociedade percebe os portadores de tuberculose a partir da sua imagem virtual, desconsiderando sua imagem real, ou seja, predomina a identidade estigmatizante, gerando a ideia de pessoas não cidadãs, sem direito a um lugar social, ao trabalho, que devem ser excluídas, abolindo sua singularidade, potencializando situaçóes de vulnerabilidade, sendo taxados como aqueles que não se encaixam no ideário da sociedade.

Conclusão: É necessário desmitificar o imaginário social que exclui o portador de tuberculose, sendo pertinente o desenvolvimento de políticas públicas com ações de educação em saúde, prevenção, informação e combate ao estigma.

> Palavras-chave: tuberculose; pesquisa qualitativa; terapia ocupacional; vulnerabilidade social.

\footnotetext{
${ }^{1}$ Universidade Federal do Rio de Janeiro. Rio de Janeiro-RJ, Brasil (thauanadossantosfernandes@ hotmail.com).

ORCID: 0000-0002-7560-4701

2 Universidade Federal do Rio de Janeiro. Rio de Janeiro-RJ, Brasil (noelle_ps@hotmail.com). ORCID: 0000-0001-8890-0780

${ }^{3}$ Universidade Federal do Rio de Janeiro. Rio de Janeiro-RJ, Brasil (marciaquadros@live.com). ORCID: 0000-0002-1310-5907

${ }^{4}$ Instituto Federal de Educação, Ciência e Tecnologia. Rio de Janeiro-RJ, Brasil (angela.silva@ ifrj.edu.br)

ORCID: 0000-0003-1917-2294
}

Recebido em: 19/07/2019 Aprovado em: 03/09/2019 Revisado em: 23/02/2020 


\section{Introdução}

A tuberculose (TB) é uma doença infectocontagiosa e transmissível que afeta prioritariamente os pulmóes. Anualmente, são notificados cerca de dez milhóes de novos casos em todo o mundo, levando mais de um milhão de pessoas a óbito. O surgimento da Aids e o aparecimento de focos de tuberculose resistente aos medicamentos tornam mais grave esse cenário (WHO, 2017).

No Brasil, a tuberculose é um sério problema da saúde pública, com profundas raízes sociais. A cada ano, são notificados aproximadamente 70 mil casos novos e ocorrem 4,5 mil mortes em decorrência da doença, apesar de ser uma enfermidade que tem cura, cujo tratamento é gratuito e disponibilizado pelo Sistema Único de Saúde - SUS (BRASIL, 2010). É uma enfermidade endêmica e para seu enfrentamento faz-se necessário realizar parcerias com diversos setores da sociedade, devido à sua complexidade.

As alterações provocadas pelo uso contínuo da medicação acabam levando ao abandono e a rupturas do tratamento, muitas das vezes independentes da vontade de seu portador, podendo acarretar resistência medicamentosa ou óbito. Tal situação - quando ocupada pelos espaços da mídia, pelos discursos políticos e da sociedade civil que valorizam os aspectos negativos do portador, ampliando a construção do preconceito e do estigma, favorecendo a ruptura dos laços afetivos, oportunizando o isolamento social e conflitos com a rede de apoio - acarreta sentimentos de menosvalia e depressão ao ser.

Segundo Heidegger (2012), “o ser não somente não pode ser definido, como também nunca se deixa determinar em seu sentido por outra coisa nem como outra coisa. O ser só pode ser determinado a partir do seu sentido como ele mesmo”. Ou seja, o ser é autônomo, independente, e indefinível, pois ele nunca se manifesta direta ou imediatamente, mas sim como ser de um ente. Nesse sentido, o ente é um modo de ser e é determinado por este, ele é tudo aquilo de que fala e que diz respeito a muitas coisas e em sentidos diferentes, é o que se é como é.

Heidegger (2012) aprofunda a questão do ser e da existência, pois parte desse ente singular e consciente que é o ser humano define como existência em toda a sua amplitude de relaçôes recíprocas entre esta (existência) e ser, e entre esta e todos os entes; por meio de um ente, que ele julga privilegiado, que é o homem. Nesse sentido, ele identifica os traços fundamentais característicos deste ser, aos quais denomina 
existenciais, subdividindo em: ser no mundo (ser de relação); transcendência (futuro, possibilidades) e temporalidade (transitório).

Ainda segundo Heidegger (2012), a relação entre sujeito e objeto é mais tempo do que espaço, pois ambos os lados coexistem e se intercomunicam. Assim, esse ser, ao se deparar com a tuberculose, precisa compreender as alteraçôes que ela faz em seu cotidiano, no seu viver e nas suas relações com o mundo (espaço) que envolvem os familiares, amigos e profissionais de saúde, entre outros, e o tempo (tratamento e cura).

Entende-se por preconceito o julgamento prematuro e inadequado sobre algo ou alguma coisa, que se manifesta numa atitude discriminatória perante pessoas, doenças, crenças, sentimentos e tendências de comportamento, sendo uma ideia formada antecipadamente e que não tem fundamento crítico ou lógico. Nesse sentido, o preconceito é a valoração negativa que se atribui às características da alteridade; implica a negação do outro diferente e, no mesmo movimento, a afirmação do próprio ser como superior/dominante (BANDEIRA; BATISTA, 2002).

O estigma, por outro lado, evidencia algo que extrapola uma atitude de prejulgamento, como sinal infamante, indigno e desonroso, uma marca na reputação de alguém e, quando vinculado à $\mathrm{TB}$, pressupôe a contaminação, o contágio, a transmissão, tornando urgente e necessário o isolamento do agente contaminador (SCHILLING; MIYASHIRO, 2008), que pode ser influenciado por determinantes sociais e demonstra relação direta com a pobreza e a exclusão, na qual o estigma tem sido considerado um indicador importante desta relação (COREIL et al., 2010).

Quando este fator se une à representatividade social dessa enfermidade pela "mancha" que fica no pulmão, após a cura da TB, amplia-se a exclusão. Nesse sentido, tudo que parece estranho acarreta evidências visíveis com atributo que diferencia o ser dos outros (GOFFMAN, 2015). Deixa de considerar o SER como uma criatura comum, reduzindo-a a uma pessoa transmissora de doença, restando para si o estigma e o descrédito sobre suas relaçóes.

O preconceito e o estigma, relacionados/direcionados ao portador de tuberculose, têm influenciado a relação desses seres nos diversos setores da sociedade, pois se encontram vinculados a situações de pobreza, prostituição e cuidados pessoais, fazendo com que sejam estigmatizados, negligenciados e marginalizados enquanto 
cidadãos, reforçando as abordagens excludentes entre outras. Para tanto, sugerese que a abordagem terapêutica aos portadores de tuberculose seja direcionada pelas particularidades de cada sujeito, considerando os aspectos de cuidado, vulnerabilidade, risco e a ampliação do acesso contínuo no âmbito do SUS (BRASIL, 2010), e por meio do acolhimento eficaz e da história de vida da pessoa.

Considerando que a terapia ocupacional (TO) é a ciência da ocupação humana, atuando nas suas principais áreas de desempenho, como as atividades diárias, trabalho, lazer e participaçáo social, ela pode contribuir para minimizar processos clínicos, como a deficiência respiratória, diminuição da sua capacidade funcional e laborativa, que, unidas à subjetividade do SER, podem obter êxito no seu cuidar. Sobretudo, porque é por meio do estudo da ocupação humana que o terapeuta ocupacional intervém nesses processos (FARIA, 2014; FARIA; VASCONCELLOS; FERREIRA, 2016).

Quanto ao aspecto legal, o Conselho Federal de Fisioterapia e Terapia Ocupacional (COFFITO) afirma que a terapia ocupacional é uma profissão do âmbito da saúde, cuja área do conhecimento centra-se na análise terapêutica de atividades: aplicadas de maneiras diretas ou indiretas, físicas ou mentais, ativas ou passivas, preventivas, corretivas ou adaptativas, abrangendo todas as fases da vida de um indivíduo (COFFITO, 2006). Ela faz parte de uma área do conhecimento voltada à prevenção e ao tratamento de indivíduos com desordens físicas, afetivas, clínicas, psíquicas, sensoriais ou sociais, decorrentes ou não de distúrbios genéticos, traumáticos, infectocontagiosos, entre outros. Concentra-se em prevenir e diminuir as incapacidades e obstáculos que surgem como consequência destes transtornos que impedem a pessoa de ter independência e autonomia.

O estudo se originou de pesquisa financiada pelo Instituto Federal do Rio de Janeiro (IFRJ) para portadores de tuberculose, atendidos pela rede de atenção básica da Zona Oeste do Rio de Janeiro, tendo como objetivo avaliar qualitativamente o estigma e o preconceito vividos pelos portadores de tuberculose no seu contexto socioafetivo, suas relaçôes, contradiçôes e subjetividades, propiciando subsídios para mudanças e transformaçôes, a partir dos dados gerados pela participação dos grupos de interesse envolvidos na avaliação, aumentando a sua capacidade de análise, para se constituírem sujeitos do processo de mudança. 


\section{Material e Métodos}

Este estudo se baseia no método hermenêutico-dialético, cuja técnica de análise possibilita a interpretaçáo dos sentidos que os sujeitos elaboram em seus discursos, e que busca a compreensão de tais sentidos face às contradiçóes que lhes constituem, e ao seu contexto social e histórico, por meio da lógica dialética. Dessa forma, enquanto a hermenêutica procura atingir o sentido do texto, a dialética dá ênfase às contradiçóes, à ruptura de sentido, porque crê na possibilidade da crítica social do tempo presente (MINAYO, 2004).

Neste sentido, Heidegger (2012) afirma que mesmo que o homem tente compreender outros elementos externos à sua rede referencial, ou entender outros "mundos" e contextos, terá que passar pelas suas próprias redes e pelos canais próprios de entendimento do mundo em que foi lançado, pois ele é o ser no mundo, pois ele é lançado no tempo e no mundo sem escolher se gostaria ou não de estar com tuberculose. Assim, ao se propor o círculo hermenêutico-dialético $(\mathrm{CDH})$ como técnica, que se utiliza de elementos da hermenêutica (mediação, acordo e unidade de sentido) e da dialética (diálogos, críticas, análises, construções e reconstruçôes individuais e coletivas) procura-se um consenso próximo da realidade estudada. Nesse viés, por meio da relação entre hermenêutica-dialética, é possível compreensão do textual, da fala e do depoimento dos sujeitos, visto que o CHD detém caráter interativo e atua como instrumento para mediar o diálogo, a reflexão e as discussōes entre os participantes, além de permitirem aos sujeitos analisarem as suas colocaçôes (NEVES, 2006; NEVES; CARNEIRO-LEÃO; FERREIRA, 2012).

Desta forma, estudo avaliativo é de natureza qualitativa, com a utilização dos pressupostos metodológicos da Avaliação de Quarta Geração, a qual foi desenvolvida por Guba e Lincoln $(1989,2011)$ e adaptada por Wetzel (2005). Caracteriza-se como avaliação construtivista realizada essencialmente pela negociação, juízos, critérios e açôes integradas, por meio do círculo hermenêutico-dialético, método que coloca em ação os autores sociais por meio de um vaivém constante, permitindo captar a realidade em estudo por meio de análise que se configura com os grupos pesquisados.

De certa forma, todos os envolvidos têm consequências no processo avaliativo, no qual a avaliação possa ser tratada e considerada como processo de aprendizagem permanente. Ela se alicerça no processo hermenêutico-dialético que ocorre pela interação e negociação do pesquisador como grupo, que, segundo Guba e Lincoln 
(1989), é o momento em que se permite a retroalimentação dos processos em curso, a fim de corrigir ou evitar erros, estabelecendo estratégias para melhorar a qualidade do cuidado prestado; onde o "consenso" é o resultado final da técnica do CHD, permitindo chegar o mais próximo possível da realidade estudada.

A sequência didática interativa se transformou em uma nova ferramenta acadêmica que utiliza o círculo hermenêutico-dialético, para trabalhar conceito/definiçôes em diferentes áreas do conhecimento, em especial para o cuidado em tuberculose, no cotidiano do viver de seu portador. Sendo assim, esta ferramenta foi utilizada como processo interativo do ensino-aprendizagem, para facilitar a integração entre pesquisadores e grupos, visando à construção e sistematizaçáo de novo conhecimento. Consequentemente, o primeiro passo foi a análise das construçôes teóricas iniciais de cada participante e, posteriormente, as construçóes coletivas (consenso) do grupo, a qual representa a realidade, ou seja, a visão final dos sujeitos.

O CHD (figura 1) é formado por três círculos. O primeiro representa os grupos, onde cada portador de TB é representado pela letra $\mathrm{R}$ (portador de TB ou familiar) e a síntese das entrevistas pela letra $C$ (construção conjunta), que responde a uma questão aberta sobre o objeto da avaliaçáo, ao qual foi solicitado que descrevesse como se realizou seu cuidado na Clínica da Saúde da Família, onde o entrevistado verbalizou suas concepçôes, ideias, valores e preocupaçôes, e questôes foram analisadas pelo avaliador, formulando a síntese e a primeira construção. $O$ segundo círculo é a dinâmica do vaivém, a qual significa a representação teórica (síntese de cada entrevista individual e grupal), onde as entrevistas foram realizadas individualmente, gravadas e transcritas na íntegra, e as falas foram identificadas pela sequência R1, R2 etc.

Neste sentido, R2 respondeu às questôes da pesquisa, e foi levada a ele a síntese de R1, para que ele fizesse novos comentários (tomar ciência das verbalizaçóes realizadas por seus antecessores), gerando novos elementos para C1 (construção conjunta). Assim sucessivamente, até que o último respondente se expressasse. $\mathrm{O}$ terceiro círculo representa o consenso, sendo o resultado de todas as entrevistas (GUBA; LINCOLN, 2011). 
Figura 1. Círculo hermenêutico-dialético (GUBA; LINCOLN, 1989)

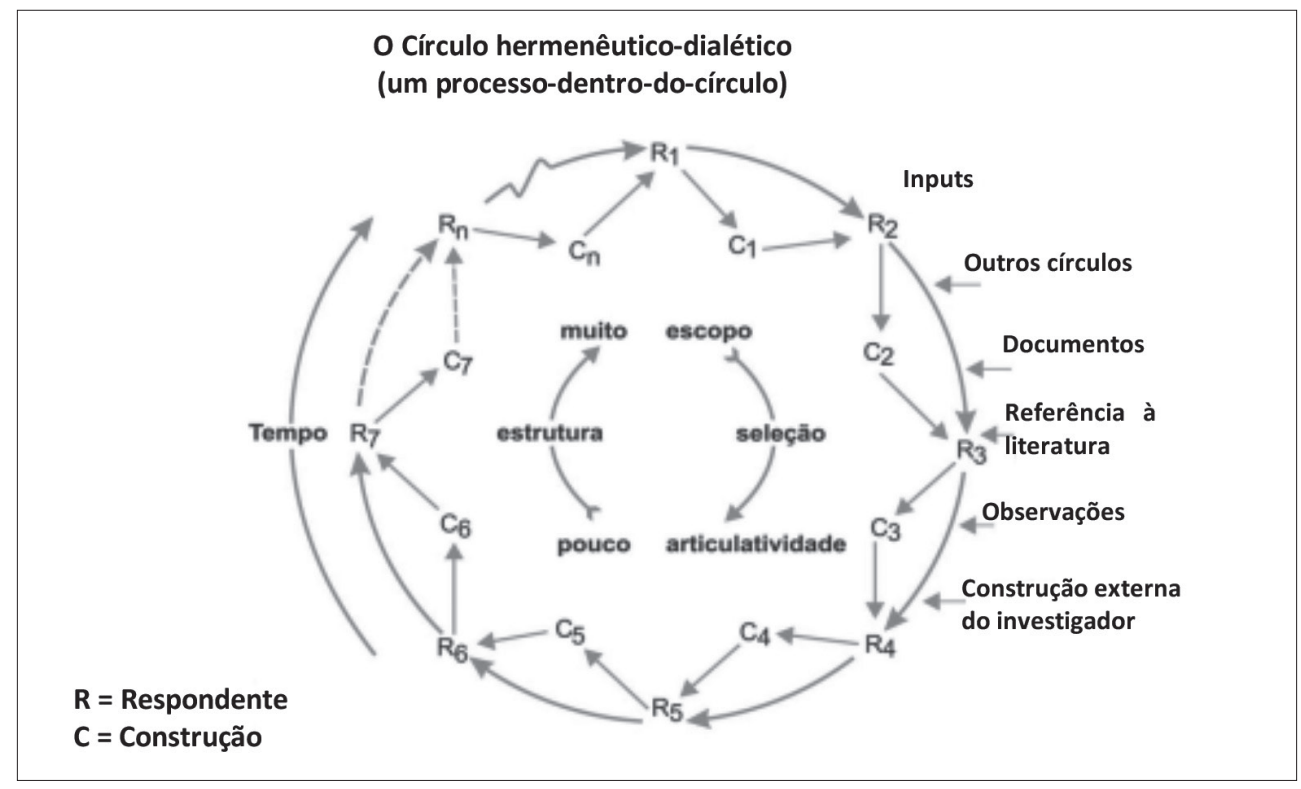

Fonte: as autoras.

Para a análise de dados, foi utilizado o método hermenêutico-dialético, que permitiu que a avaliaçáo ocorresse de maneira concomitante à coleta de dados. Esse método apresenta duas etapas: identificaçáo das unidades de informação e categorizaçáo. As unidades de informação são sentenças ou parágrafos obtidos do material empírico, registradas de modo compreensível a qualquer leitor, e náo somente ao pesquisador. Logo, a maior contribuição dada pelo emprego desta técnica diz respeito à pré-análise dos dados obtidos na entrevista com cada pessoa, e por ocasiáo da reuniáo final com o grupo entrevistado. Esse procedimento, além de minimizar a subjetividade do pesquisador, também facilita a elaboração da síntese final dos dados coletados e a validaçáo do estudo. Como a técnica do CHD náo tem nenhum esquema fechado, conforme Guba e Lincoln (1989), foram utilizadas adaptaçóes segundo as peculiaridades de cada contexto pesquisado (pessoa, família, instituição etc.).

Os dados foram coletados por meio da observaçáo, momento no qual o avaliador interagiu sem estar engajado com as atividades de avaliação, a qual foi registrada em diário de campo. Essa etapa totalizou 120 horas, tendo por objetivo apreender a dinâmica do cuidado ao portador de TB, a interaçáo de sua família e a forma com que se construíram os sentidos em relação à prática das atividades grupais. Fizeram 
parte da pesquisa 24 portadores de tuberculose e 16 familiares, que frequentavam uma Clínica da Saúde da Família (CSF) do município do Rio de Janeiro. Adotou-se como critério de inclusão todos participantes terem boas condições de comunicação, sendo excluídos aqueles que estivessem com outras comorbidades como alcoolismo, dependência de drogas e déficit cognitivo importante. Além deles, fizeram parte também da pesquisa três acadêmicos e duas terapeutas ocupacionais.

Oliveira (2008) fala sobre os tipos de categorias esclarecendo que elas podem ser teóricas, quando se referem às leituras convergentes ao tema central do estudo (tuberculose), ou melhor dizendo, a partir da definição do tema central, que permite construir os instrumentos de pesquisa, seja questionário e/ou roteiro de entrevista. Tais instrumentos passam a ser denominados categorias empíricas, e as respostas a estes instrumentos são chamadas de unidades de análise.

Houve duas fontes de dados: a primeira representada pelo CHD, no qual emergiram construçóes conjuntas de cada grupo; a segunda, pelas observaçóes de campo, informaçóes originárias das entrevistas que se transformaram em observaçóes produtivas e representaçóes iconográficas das oficinas de terapia ocupacional. Tevese o cuidado de não tomar como verdade a ser generalizada, mas sim, como mais um conhecimento a ser considerado de forma crítica em relação ao contexto, pois seria ingenuidade pensar que o avaliador não tem conhecimento prévio e opiniōes sobre este tipo de cuidado.

\section{Quadiro 1. Construçẫo do círculo hermenêutico-dialético da Família}

\begin{tabular}{|c|c|c|c|c|c|}
\hline & Familiar 1 & Familiar 2 & Familiar 3 & Familiar 4 & Etc. \\
\hline $\begin{array}{l}\text { Questóes } \\
\text { iniciais }\end{array}$ & \multicolumn{5}{|c|}{$\begin{array}{l}\text { 1- Fale sobre o seu atendimento no cuidado } \\
\text { 2- Como o cuidar do seu familiar ocorre nesta unidade? } \\
\text { 3- Você já percebeu alguma postura de exclusão em relação à TB nesta unidade? }\end{array}$} \\
\hline $\begin{array}{l}\text { Questóes } \\
\text { desdobradas }\end{array}$ & $\begin{array}{c}\text { Relacionamento } \\
\text { dos clientes com } \\
\text { seus familiares e } \\
\text { outros clientes } \\
\text { Apoio familiar } \\
\text { Açóes que visem } \\
\text { a diminuir o } \\
\text { preconceito }\end{array}$ & $\begin{array}{l}\text { Sobrecarga do } \\
\text { familiar } \\
\text { Atividades } \\
\text { realizadas pelo } \\
\text { cliente fora } \\
\text { da Clínica da } \\
\text { Família }\end{array}$ & $\begin{array}{l}\text { Grupo de cuidar } \\
\text { do cuidador } \\
\text { Preconceito e } \\
\text { discriminação } \\
\text { relacionados à } \\
\text { TB/Aids }\end{array}$ & $\begin{array}{c}\text { Atendimento } \\
\text { em domicílio } \\
\text { pela Clínica da } \\
\text { Família } \\
\text { E preconceito } \\
\text { dos profissionais } \\
\text { da CSF }\end{array}$ & $\begin{array}{c}\text { Grupo de } \\
\text { família como } \\
\text { espaço de } \\
\text { comunicaçáo } \\
\text { entre famílias }\end{array}$ \\
\hline
\end{tabular}

Fonte: as autoras. 
Os quadros 1 e 2 dizem respeito às questôes norteadoras iniciais e às questôes desdobradas na sequência de entrevistas em cada grupo (família e cliente).

Quadiro 2. Construção do círculo hermenêutico-dialético do cliente

\begin{tabular}{|l|l|l|l|l|l|}
\hline & Portador 1 & Portador 2 & Portador 3 & Portador 4 & Etc. \\
\hline $\begin{array}{l}\text { Questóes } \\
\text { iniciais }\end{array}$ & $\begin{array}{l}\text { 1- Fale sobre o seu atendimento no cuidado } \\
\text { 2- Como o seu cuidar ocorre nesta unidade? } \\
\text { 3- Você já percebeu alguma postura de exclusão em relação à TB nesta unidade? }\end{array}$ \\
\hline $\begin{array}{l}\text { Questóes } \\
\text { desdobradas }\end{array}$ & $\begin{array}{l}\text { Manejo do } \\
\text { atendimento. } \\
\text { Dedicação dos } \\
\text { profissionais } \\
\text { Atendimento } \\
\text { domiciliar }\end{array}$ & $\begin{array}{l}\text { Discriminação } \\
\text { co cliente no } \\
\text { Comordado }\end{array}$ & $\begin{array}{l}\text { Dificuldade } \\
\text { da ingesta da } \\
\text { medicaçáo } \\
\text { e os efeitos } \\
\text { colaterais } \\
\text { Medo de } \\
\text { morrer }\end{array}$ & $\begin{array}{l}\text { Atendimento } \\
\text { no posto e } \\
\text { encaminhamento } \\
\text { ao hospital } \\
\text { pela rejeição ao } \\
\text { medicamento e/ } \\
\text { ou abandono de }\end{array}$ & $\begin{array}{l}\text { Inserção de } \\
\text { oficinas de } \\
\text { cuidado e de }\end{array}$ \\
\hline
\end{tabular}

Fonte: as autoras.

Para tanto, a dinâmica do círculo consistiu em entrevistar todos os portadores de TB e seus familiares de maneira sequenciada e sistemática, coletando as construçóes teóricas individuais do primeiro ao último e retornando ao segundo. Havia a possibilidade de cada um dos participantes verificarem as construçôes dos outros, podendo modificar, excluir ou reorganizar a sua ou náo, a partir do que foi explicitado pelo sujeito anterior, finalizando o círculo (NEVES, 2006; NEVES, CARNEIRO-LEÃO, FERREIRA, 2012).

Para analisar os dados, foram realizadas três oficinas com todos os pesquisadores e acadêmicos, tendo o objetivo construir o processo coletivo e formativo de análise de dados empíricos dos participantes da pesquisa, visando compreender como o estigma e o preconceito encontravam-se presentes no viver do portador de TB e de sua família:

- Primeira oficina - Os pesquisadores foram divididos em grupos de trabalho por cores, conforme o grupo de interesse: portador e familiar. A partir disso, eles organizaram-se em duplas, recebendo duas entrevistas, cuja tarefa era identificar e fazer a síntese das unidades de informação, organizando-as em eixos temáticos. Em seguida, essas duplas se reuniram, fazendo nova síntese das informaçôes, delimitando o conjunto de informaçóes relacionadas a seu grupo de interesse, até conseguir analisar a totalidade de entrevistas, devendo trazer quadros com unidades de informação, eixos temáticos e respectivas falas sistematizadas. 
- Segunda oficina - Realizada em plenária, os integrantes das oficinas se reuniram, e cada dupla apresentou o quadro com as unidades de informação extraídas a partir das entrevistas. Essa apresentação possibilitou a delimitação de unidades temáticas mais abrangentes e a elaboração de síntese. Foram compostos coletivamente os quadros dos grupos de interesse e definidas as unidades de informação e núcleos temáticos centrais da análise da avaliação qualitativa, gerando marcadores internos e externos.

- Terceira oficina - Foram apresentadas e discutidas as conceituaçóes de cada marcador, sendo estabelecido que as análises seguissem a orientação teórica já utilizada na etapa da avaliação qualitativa, enfocando a estrutura, o processo e os resultados. A partir desta orientação teórica mais ampla, foram desdobrados os seguintes marcadores (quadro 3).

Quadro 3. Marcadores internos e externos

\begin{tabular}{|l|l|}
\hline \multicolumn{1}{|c|}{ Marcadores internos } & \multicolumn{1}{c|}{ Marcadores externos } \\
\hline Estrutura: PSF & $\begin{array}{l}\text { Articulação da rede de saúde com familiares e } \\
\text { cliente - CUIDAR }\end{array}$ \\
\hline $\begin{array}{l}\text { Processo de trabalho dos pesquisadores: } \\
\text { - Atividade como suporte de cuidar } \\
\text { - Inserção familiar }\end{array}$ & - Relação da comunidade frente à tuberculose/Aids \\
- Oficinas de terapia ocupacional & - Espaço aberto para verbalização dos grupos \\
\hline
\end{tabular}

Fonte: as autoras.

Os eixos temáticos identificados e apresentados na negociação foram os seguintes:

- Grupo de familiar: o cuidado em TB (abordando aspectos relacionados ao atendimento a essa enfermidade na Clínica de Saúde da Família e no Centro de Saúde); o cuidado em saúde e os familiares (questôes sobre o adoecimento e sobrecarga familiar, dificuldade de cuidar no ambiente familiar e questóes de contágio); necessidades de melhorias (medicação, diminuir resistência medicamentosa e relação com os medicamentos, maior atenção dos profissionais, atendimento residencial, desconstrução de preconceitos).

- Grupo de clientes: o cuidado em domicílio e no posto (pontos em que a CSF tem se destacado como referência de cuidado em TB, atendimento ao portador, estrutura do CSF), o acolhimento realizado pela terapia ocupacional, o 
estigma vivenciado por alguns profissionais do posto, a dificuldade da ingesta da medicação e o medo de morte.

- Quarta oficina: a preparação da negociação foi realizada mediante a utilização da técnica grupal, em que as construçóes eram oriundas de seu grupo, objetivando sua apresentação para que os portadores e familiares pudessem ter acesso a todas as informações de cada grupo e pudessem modificá-las ou confirmá-las. Esses encontros ocorreram em salas com privacidade, para que todos se sentissem tranquilos ao expor suas opinióes. Em cada grupo, um dos pesquisadores se encarregou da apresentação do material organizado na etapa anterior; dois atuaram como observadores, registrando o que foi discutido no grupo e, quando necessário, lançando questóes que pudessem esclarecer determinado ponto. Ao final da negociação, encerrou-se o trabalho de campo e iniciou-se a análise final dos dados para se elaborar o relatório da pesquisa, que envolveu as seguintes atividades: transcrição dos dados empíricos, organização do banco de dados, organização e análise dos dados. A categorizaçáo teve o objetivo de unificar todas as unidades de informação relacionadas ao mesmo conteúdo, buscando-se a consistência interna das categorias após a negociação, construindo as categorias definitivas ou eixos temáticos (GUBA; LINCOLN, 1989).

A partir dessas oficinas, cada grupo de trabalho retomou todo o material pertinente ao caso estudado (entrevistas, diários de campo, documentos, sínteses das oficinas, análise iconográficas, banco de referências bibliográficas) e procedeu à elaboração do relatório de estudo, o "consenso", o qual foi desenvolvido no intervalo entre as oficinas e a elaboraçáo do relatório, seguindo-se rigorosamente a metodologia de Avaliação de Quarta Geração, configurando-se o processo formativo e construtivista do CHD.

A análise dos dados, tanto na aplicação do CHD na pesquisa de campo por meio da metodologia interativa, bem como na realização da sequência didático-interativa (SDI) no contexto do processo ensino/aprendizagem, foi trabalhada pela triangulação do referencial teórico da temática em estudo com os dados coletados, leituras de documentos, registros em cadernos de campo, observaçôes e depoimentos. Este procedimento se respalda na teoria de análise de conteúdo de Bardin e na análise hermenêutico-dialética, cujo foco central foi o estudo do estigma e preconceito da TB. 
Com base nos dados obtidos no CHD, levantou-se como principal categoria teórica a tuberculose e seu tratamento, e como categorias empíricas o cuidado realizado no SUS a presença do estigma e do preconceito nesse cuidado. Uma vez definida a classificação das categorias, passou-se à construção da matriz geral dos dados obtidos, incluindo a sistematização das respostas dadas pelos participantes de cada grupo. Quanto às categorias geradas neste estudo, foram estigma e preconceito: no relacionamento social e familiar; em relação ao trabalho e como eles são percebidos pelos familiares.

Assim, foi possível observar que os participantes foram mais subjetivos em suas concepçóes, uma vez que quase todos os grupos enfatizaram a abordagem do estigma e do preconceito presentes nas faces das pessoas dos postos, sejam eles profissionais ou usuários. Deste modo, o processo avaliativo se evidenciou devido ao tratamento dos dados, mostrando ser necessário enfatizar mais as seguintes questôes: concepção, acesso e articulação da rede, mídia, tuberculose, preconceito e estigma, campanhas de prevenção e de esclarecimento, características do trabalho em tuberculose, do cliente e o perfil laborativo desse ser.

Os princípios éticos foram assegurados conforme a Resolução no 466/12 do Conselho Nacional de Saúde, do Ministério da Saúde (BRASIL, 2012), e o projeto foi aprovado pelo Comitê de Ética da Secretaria Municipal de Saúde do Rio de Janeiro sob no 0149.0.314.000- 10, e todos os participantes assinaram o Termo de Consentimento Livre e Esclarecido (TCLE).

\section{Resultados e Discussão}

No processo avaliativo, temas como preconceito e estigma, relacionados ao portador de tuberculose, foram apontados várias vezes. Esses clientes se referiram a consequências negativas por serem rotulados e estereotipados como seres indesejáveis e improdutivos, homossexuais ou prostitutas, o que lhes projetou posicionamento muito baixo na hierarquia social, interferindo negativamente em suas oportunidades de cidadão e da vida em sociedade 
Quadro 4. Matriz geral dos dados do grupo de portadores de tuberculose e seus familiares

\begin{tabular}{|c|c|}
\hline Categorias Empíricas & Unidades de Análise Portador de Tuberculose \\
\hline \multirow{4}{*}{$\begin{array}{l}\text { Estigma e preconceito } \\
\text { no relacionamento } \\
\text { social e familiar }\end{array}$} & $\begin{array}{l}\text { Minha irmã nem chegava perto de mim. Quando ela trazia a } \\
\text { comida, colocava na porta e avisava e saía correndo. Eu falava que a } \\
\text { TB náo contamina assim, mas ela dizia que não ia ser contaminada, } \\
\text { que ela se cuidava e não era como eu (P5). }\end{array}$ \\
\hline & $\begin{array}{l}\text { Meu corpo diz que tenho uma doença ruim. Se eu uso a máscara, todos } \\
\text { se afastam mais ainda. Lá em casa, só quem sabe que tenho isso (TB) é } \\
\text { a minha mulher. As pessoas desconfiam que eu tenho um bicho ruim, } \\
\text { mas ruim mesmo, dentro de mim, pois fiquei fraquinho e emagreci } \\
\text { muito. Porque tive reação ao remédio, ele é muito forte. Vomito, perco } \\
\text { as forças... O remédio acaba com qualquer pessoa. (P10). }\end{array}$ \\
\hline & $\begin{array}{l}\text { Ninguém chega perto... Separam tudo... Como é que eu vou fazer } \\
\text { parte de um grupo (familiares e clientes), se eles têm preconceito } \\
\text { entre eles mesmos? É difícil viver assim... Olha para um lado, vê } \\
\text { recriminação; olha pro outro, vê rejeiçâo... É difícil (P3). }\end{array}$ \\
\hline & $\begin{array}{l}\text { Eu tenho tuberculose. Se meus vizinhos souberem, eles me } \\
\text { expulsam daqui. Eles podem ser marginais, mas eu serei vista } \\
\text { como pior pessoa do mundo. Fico calada, tenho medo... podem me } \\
\text { machucar muito... Lá (comunidade) é muito pior... se souberem } \\
\text { que estou com TB.... (P9). }\end{array}$ \\
\hline \multirow{2}{*}{$\begin{array}{l}\text { Estigma e preconceito } \\
\text { nas relaçóes de } \\
\text { trabalho }\end{array}$} & $\begin{array}{l}\text { Estou terminando o tratamento, devo ter alta hoje. Consegui um } \\
\text { emprego. Näo, não falei para o dono (empresa) que estava fazendo } \\
\text { tratamento para TB; se ele souber, não emprega. Estou precisando de } \\
\text { dinheiro. Disse que fazia acompanhamento no HU para outra coisa. } \\
\text { Tuberculose. Nunca! (P8). }\end{array}$ \\
\hline & $\begin{array}{l}\text { Penso que o governo devia falar que nós (clientes) não somos sujos, } \\
\text { pobres, ou homossexuais. Somos gente. Gente, sim, não precisa sair } \\
\text { correndo com medo de pegar essa coisa ruim (TB)... Ela é ruim, sabe, } \\
\text { perdi minha mulher, meu trabalho... Ninguém me quer. Meu patrão } \\
\text { não me deixa entrar no portão. Como vou me manter?... (P4). }\end{array}$ \\
\hline
\end{tabular}




\begin{tabular}{|l|l|}
\hline Categorias Empíricas & Unidades de Análise do Grupo Família \\
\hline \multirow{5}{*}{$\begin{array}{l}\text { Estigma e preconceito } \\
\text { percebido pelo }\end{array}$} & $\begin{array}{l}\text { Meu filho náo vai pegar os remédios. Primeiro porque tem vergonha } \\
\text { fe se expor e ser discriminado, segundo que ele é homossexual e ele diz } \\
\text { que as pessoas ficam olhando para ele de modo estanho. Então ele não } \\
\text { vai. Eu vou ou o agente traz aqui... Sei que ele não quer ser apontado } \\
\text { como "tuberculoso". Isso é terrivel (F4). }\end{array}$ \\
\cline { 2 - 2 } & $\begin{array}{l}\text { Quando vou no posto, muitas das vezes fico sem jeito das pessoas } \\
\text { acharem que quem tem TB sou eu e não meu marido (F2). }\end{array}$ \\
\cline { 2 - 2 } & $\begin{array}{l}\text { Eu prefiro que a mulher do posto venha trazer os remédios aqui em casa, } \\
\text { pois ninguém precisa saber da doença que aqui mora também (F1). }\end{array}$ \\
\cline { 2 - 2 } & $\begin{array}{l}\text { Sabe, muitas das vezes eu sinto que o agente que vem aqui em casa } \\
\text { tem medo de pegar "essa doença", ele entrega os remédios na porta e } \\
\text { diz que tem que fazer outras visitas (F3). }\end{array}$ \\
\hline
\end{tabular}

Fonte: as autoras.

Essa enfermidade foi identificada como peste branca (BITTENCOURT, 2000) por afetar os pulmóes e como a representação da tuberculose no imaginário social encontra-se vinculada à promiscuidade, sujeira e boemia, assim eles precisavam se ocultar, buscando se "limpar" para não contaminar outras pessoas. Assim sendo, na sociedade na qual eles estão incluídos acredita-se que, às vezes, eles não são considerados cidadãos, e sim vetores da doença. Por isso, para não serem agredidos, como se pode observar nas falas de P3, P5, P9, etc., eles optam por ocultar seu diagnóstico.

Diante disso, a perda de status social tornou-se a base da discriminação, ocasionada pela rotulação, estereotipia e isolamento (GOFFMAN, 2015). Assim, os portadores de TB foram taxados e considerados sujeitos fora do contexto social - aqueles que não se encaixam no ideário da sociedade (sem vínculos familiares, emprego formal e moradia), inclusive que os mesmos devem ser excluídos pelo seu desleixo com sua saúde.

O enfrentamento do cuidado ao corpo com TB que passa pelo tratamento quimioterápico, conforme diretrizes do Ministério Saúde (2012), pode desencadear reaçôes adversas. O paciente fica mais vulnerável a doenças oportunistas, com fragilidade física, devido à diminuição de sua capacidade funcional e respiratória, que dificulta a realização das atividades cotidianas como subir e descer morro para ir ao hospital, realizar atividades da vida diária que necessite elevar os braços acima 
de $90^{\circ}$ (arrumar compras no armário), gerando maior grau de dependência do outro (família/empregador), segregação e abandono do tratamento.

A promoção da saúde deve se orientar pela na produção da vida laborativa e comunitária, que sofre a influência do preconceito e do estigma, processos sociais resultantes da discriminação, envolvendo categorização, estereótipos e rejeição social (PARKER, 2012), situaçóes estas que afastam a possibilidade de se obter um emprego formal, pois muitos empregadores pensam que a TB poderá se alastrar em sua empresa, acarretando vários afastamentos do trabalho, além de imaginar que, apesar da cura, o portador será sempre uma pessoa doente, sem resistência física e que faltará muito ao labor diário, trazendo gastos e "manchando" esse local de labuta. Essa ideia gera distorção emocional, afetando a vida do cliente e de sua família, pois o SER precisa de autovalorização e de ser inserido no mercado de trabalho formal.

Desta forma, a pessoa estigmatizada gera duas identidades: a real e a virtual. A real identificada como o conjunto de atributos que ela tem e a virtual representando a percepção que as pessoas do seu entorno têm dela; logo, são exigências e atribuiçôes de caráter, feitas pelos considerados normais (GOFFMAN, 2015). Portanto, a imagem virtual dos clientes de TB é reconhecida como identidade deteriorada pelos valores morais, representando algo ruim dentro da comunidade, devendo ser evitado o convívio com os mesmos, fazendo com que passe por indisciplinado, imoral. Isso favorece a atitude preconceituosa e discriminatória, gerando vulnerabilidade, constituindo-se em barreira social e afetiva, cujo diagnóstico implica o juízo de valor e, em decorrência, a segregaçáo (CIRINO, 2009).

Diante do exposto, para que o portador de TB não receba rótulos predeterminados, sem medos e sem a ideia de que é um problema - ou um perigo -, os profissionais de saúde e a família têm a tarefa de se engajar no desafio de amparar esse SER a concluir seu tratamento e se fortalecer, por meio do FAZER, que é a prática da terapia ocupacional.

Estudos como os de Macq et al. (2006) e Weiss et al. (2008) - que criaram escalas validadas para avaliar o estigma da TB pelos familiares dos enfermos na Nicarágua, Sul da Tailândia, Malawi, Bangladesh e Índia, por meio de questionário com 10 questôes - abrangiam os seguintes domínios-chave: medo de transmitir a doença, atitudes associadas à vergonha, ao julgamento e à revelaçáo da doença.

Desta forma, foi observado nas verbalizaçóes nos grupos de interesse dos portadores de $\mathrm{TB}$ e familiares faces preconceituosas e de medo por parte dos 
profissionais de saúde que os atendem. Para que isso não ocorra, se faz necessário que haja a destituição de preconceitos e prejulgamentos e que se lance mão de uma assistência mais humanizada, com foco no acolhimento, na escuta sensível, da conscientização desses profissionais sobre a doença caracterizada pela destituição de preconceitos, alicerçada na relação de ajuda, e que essa assistência seja viabilizada pela mudança de atitudes, na busca de conhecimentos, no aperfeiçoamento de habilidades e no reconhecimento da existência do outro, a partir do inexistente (PEREIRA; VARGAS; OLIVEIRA, 2012).

Outro aspecto observado foi a não ocorrência da reconstrução no vaivém das respostas dos dois grupos participantes na dinâmica do CHD. Pois, ao serem indagados quanto à possibilidade de reverem suas consideraçóes em relação ao (s) sujeito (s) anterior (es), os participantes (portadores de TB e familiares) não desejaram modificá-la e permaneceram com sua própria consideração. Essa condição já foi apontada por Neves (2006), explicitando que isso pode acontecer e que as mudanças teóricas não ocorrem de forma clara. Mas as informaçóes apresentadas aos sujeitos de alguma forma foram captadas e revisadas, colaborando para um resultado final onde ocorreu encontro de consenso (realidade), em que todos os participantes discutiram sobre suas consideraçôes iniciais sobre o estigma e o preconceito da tuberculose. Chegaram assim a uma única concepção: a tuberculose ainda é excludente.

No momento do consenso, observou-se melhor a organização das ideias, mas ainda com permanência de obstáculos de aprendizagem por meio de terminologia não adequada ao conteúdo ou com ideias muito vagas. Contudo, isso era de se esperar, pois os participantes deste estudo encontram-se em diferentes níveis desenvolvimento cognitivo e de escolaridade (analfabeto a superior completo), onde os conceitos e as ideias ainda estâo sendo estruturadas, pois muitos utilizam o conhecimento do senso comum. Sendo assim, é possível demonstrar que o fator de interação social do CHD possibilitou ao SER interpretar, complementar, observar e refazer os fatos decorridos por outro, o que para Araújo et al. (2010) é fator relevante no CHD, visto que proporciona revisão, permite construir e reconstruir falas e proporciona reflexão adequada sobre o conceito trabalhado.

$\mathrm{O}$ consenso do $\mathrm{CHD}$ explicitado pelos grupos pesquisados foi que viver com tuberculose é muito difícil, não só pelo tratamento que traz consequência que pode levar a óbito, como principalmente pela presença constante do estigma e do preconceito, que afasta os clientes de TB do seu viver social, familiar e laborativo. 
Eles perceberam a dualidade da sociedade e da família: se de um lado a sociedade discrimina, por outro ele não deseja ser condenado e nem vitimizado. A família também viveu essa dicotomia, pois de um lado clama pela ajuda; por outro, vivenciou o medo nas faces de quem cuida, gerando desafios e fragilidades a serem enfrentados diariamente.

Existe, claramente, a necessidade de mudar esta cultura de exclusão. Embora seja um processo lento e gradual, deve ser cada vez mais incentivado pelos setores da política, da saúde e do trabalho. Esta perspectiva vem ao encontro do estudo de Pereira, Vargas e Oliveira (2012), esclarecendo que "a desconstrução do paradigma de exclusão da pessoa que tem uma existência-sofrimento ocorre pela construção de um novo, que traz a perspectiva de conviver com as diferenças". Ou seja, a problemática do portador de TB mostra o quanto ainda a sociedade precisa amadurecer conceitos a respeito dessa enfermidade e incluir valores que possam agregar à saúde e ao trabalho. Desta maneira, eles não necessitaram ocultar a doença para obter trabalho ou ser inserido na família e na comunidade.

$\mathrm{O}$ preconceito e a estigmatização em relação ao portador de TB mascaram, muitas vezes, a real situação de vulnerabilidade em que o mesmo se encontra. A estigmatização é identificada na produção de violência física e verbal praticada por alguém do seu convívio diário, podendo ou não ser familiar. A partir da vivência nas comunidades, fica perceptível a falta de oportunidades de trabalho formal, incentivando o portador a permanecer em auxílio doença e não se vincular a uma atividade laborativa. Por outro lado, as deficiências de infraestrutura de moradia, a situação de aglomeraçôes comunitárias, falhas do Estado em cuidar, favorecendo a expansão da doença, e o desconhecimento por parte dos empresários sobre a história da TB. Além disso, deve ser incentivado, no meio empresarial, que a tuberculose é uma enfermidade que tem cura, que após 30 dias de tratamento não existe o problema de contaminação, esclarecendo os meios de propagação dela, tratamento e cura, visando à inserção desse SER no mundo do trabalho.

\section{Conclusão}

O trabalho de campo possibilitou constatar a forte adesão ao método de Avaliação de Quarta Geração não só por parte dos grupos de interesse, o qual enfatizou o empoderamento dos familiares e clientes enquanto protagonistas do processo avaliativo, como também por parte dos pesquisadores, pois exigiu qualificação do 
processo avaliativo, desenvolvendo a dimensão formativa, aprimorando a capacidade de análise, possibilitando o aprofundamento na discussão e delimitação dos temas oriundos da avaliação.

Essa dimensão teve seus limites atrelados a pouca tradição que clientes e familiares têm em discutirem seus problemas e dificuldades de forma coletiva no cotidiano dos cuidados, principalmente vinculados ao cuidado da terapia ocupacional. A Avaliação de Quarta Geraçấo constitui-se como importante possibilidade metodológica no campo da avaliação de cuidados e programas de saúde, na medida em que possibilitou o acesso às dimensões qualitativas, pouco acessadas pelos indicadores e que, no entanto, influenciou no que se refere ao cuidado ao cliente com TB e sua família.

A utilização do círculo hermenêutico-dialético (CHD) como ferramenta para coleta de dados possibilitou, por seu caráter dinâmico e interativo, a reconstrução de conceitos e a superação de equívocos conceituais que porventura poderiam comprometer o estudo. Além de contribuir para que os participantes pudessem superar suas dificuldades, inseguranças, dúvidas e incertezas. As limitaçóes da metodologia referentes ao processo hermenêutico-dialético estabeleceram o foco da avaliação, permitindo a emersão de grande volume de dados, não sendo possível que todos fossem contemplados, devido aos limites de tempo e recursos inerentes a qualquer pesquisa.

Já a etapa de negociação possibilitou momentos de reflexão e debates sobre as questôes mais críticas em relação ao modo de atenção ao portador de TB, estabelecendo espaço de discussão frente às mudanças necessárias para se promoverem avanços no cuidado da terapia ocupacional na tuberculose, reforçando as contribuiçôes da inserção deste profissional no SUS.

O processo avaliativo evidenciou que a sociedade percebeu o portador de tuberculose a partir da sua imagem virtual, desconsiderando sua imagem real, ou seja, não o vê enquanto pessoa singular, que tem uma história de vida, sentimentos, desejos, aprendizados, perdas e ganhos. Predomina a identidade estigmatizante de pobre, magro e homossexual, gerando a ideia de exclusão. Com isso, a construção de vida do portador de tuberculose é orientada pelo estigma e preconceito, resultando em discriminação e resistência em conviver com pessoas, instituiçôes etc.

As informaçôes preconceituosas a respeito do portador de tuberculose e a maneira como ele é tratado geram discussóes que podem ser estratégicas para o aumento ou a diminuiçâo do estigma e da discriminaçâo. É preciso problematizar as práticas e 
os saberes, informando o real conceito dessa enfermidade, seu tratamento, modo de contágio e capacidade funcional, em oposição ao clima emocional mobilizado pela concepção preconceituosa que fragiliza a vida do cliente e de sua família, valorizando os aspectos negativos do SER.

A pessoa com TB vive em um território onde existem múltiplas disputas e políticas de distintos atores, onde o poder e a força são predominantes e o mundo adota valores e concepçôes direcionadas por normas moralistas, cujas histórias de vida são menosprezadas e relegadas ao segundo plano. Nesse sentido, entender o preconceito diante desta doença possibilita processo de inclusão, revertendo-se em conscientização, empregabilidade e acolhimento, resultando em maior acesso desses clientes às redes de cuidado e ampliando as políticas públicas com o direcionamento de ações afirmativas e açôes de prevenção, reabilitação e reinserção profissional e social a esse SER.

Considera-se que este estudo, dentro do processo participativo de avaliação, deu voz aos portadores de TB e seus familiares, promovendo reflexóes sobre preconceito e estigma, possibilitando espaço de discussão e mudanças necessárias no enfrentamento da discriminação. A metodologia não estabeleceu o foco da avaliação a priori, mas se associou à pouca tradição destes grupos (cliente e família) a serem incluídos em debates sobre a sistemática de acolher e do cuidar, fatos esses que podem ter sido um impeditivo para que todos dados fossem contemplados nas reuniōes de negociação.

Conclui-se que a questão da tuberculose é de todos - clientes, famílias, profissionais, políticos e todos os cidadãos. Cada um deve agir dentro do seu campo, da sua área de abrangência, para que os portadores de TB possam ser cuidados, acolhidos e depois reinseridos nos empregos e na sociedade repleta de diferentes. ${ }^{1}$

\section{Referências}

ARAÚJO, A. F. et al. Círculo hermenêutico-dialético como ferramenta didática para trabalhar as questóes relativas a educação ambiental. Anais Resumos... Natal: SBPC, 2010. Disponível em: $<$ http://www.sbpcnet.org.br/livro/62ra/resumos/resumos/1306.htm>. Acesso em: 12 mar 2018. BANDEIRA, L.; BATISTA, A. S. Preconceito e discriminação como expressões de violência. Rev. Estud. Fem. [online], v. 10, n. 1, p. 119-141, 2002. http://dx.doi.org/ 10.1590/S0104026X2002000100007. Acesso em: 12 mar 2018.

BITTENCOURT, T.M. Peste branca - arquitetura branca: os sanatórios de tuberculose no Brasil na primeira metade do século 20 / São Carlos; 2000. Dissertação (Mestrado em Engenharia) Escola de Engenharia de São Carlos, Universidade de São Paulo, 2000. 
BRASIL. Ministério da Saúde. Secretaria de Atenção à Saúde. Departamento de Ações Programáticas Estratégicas. Abordagens terapêuticas aos portadores de tuberculose e AIDS no Sistema Único de Saúde. Brasília: MS, 2010.

BRASIL. Ministério da Saúde. Conselho Nacional de Saúde. Comitê Nacional de Ética em Pesquisa em Seres Humanos. Resolução no 466, de 12 de dezembro de 1996. Dispóe sobre as diretrizes e normas regulamentadoras de pesquisa envolvendo seres humanos. Brasília: Ministério da Saúde, 2012.

CIRINO, O. Diagnóstico e segregação. Diálogos, v. 6, n. 6, p. 32-5, 2009.

CONSELHO NACIONAL DE FISIOTERAPIA E TERAPIA OCUPACIONAL COFITTO. Resolução no 316, de 19 de julho de 2006. Disponível em: http://coffito.gov.br/ nsite. Acesso em 12 jan 2017.

COREIL, J. et al. Structural forces and the production of TB related Stigma among Haitians in two contexts. Soc Sci Med, v. 71, n. 8, p. 1409-1417, 2010.

FARIA, R. De que atividadelocupação estamos falando? Um estudo sobre a produção científica da Terapia Ocupacional, Trabalho e Saúde. Dissertação (Mestrado Saúde Publica) Escola Nacional de Saúde Pública Sergio Arouca/Ensp, Fiocruz, Rio de Janeiro, 2014.

FARIA, R. S.; VASCONCELLOS, L. C. F.; FERREIRA, D. M. T. P. A produção científica sobre terapia ocupacional: o silenciamento da relação trabalho-saúde. Trab. educ. saúde, n. 1, v. 3, p. 905-24, jul-set, 2016.

GOFFMAN, E. Estigma: notas sobre a manipulação da identidade deteriorada. Rio de Janeiro: LTC; 2015.

GUBA, E. G.; LINCOLN, Y. S. Avaliação de Quarta Geração. São Paulo: Unicamp; 2011. . Fourth Generation Evaluation. Newbury: Sage, 1989.

HEIDEGGER, M. Ser e tempo. Campinas: Editora da Unicamp, Petrópolis: Vozes; 2012.

MACQ, J. et al. An exploration of the social stigma of tuberculosis in five "municipals" of Nicaragua to reflect on local interventions. Health Policy, v. 74, n. 2, p. 205-217, 2006.

MINAYO, M. C. S. Pesquisa social: teoria, método e criatividade. Petrópolis: Vozes, 2004.

NEVES, R. F. A interação do ciclo da experiência de Kelly com o círculo hermenêutico-dialético, para a construção de conceitos de biologia. 2006. 108f. Dissertação (Mestrado em Ensino das Ciências) - Universidade Federal Rural de Pernambuco, Recife, 2006

NEVES, R. F.; CARNEIRO-LEÃO, A. M. A.; FERREIRA, H. S. A interação do ciclo da experiência de Kelly com o círculo hermenêutico-dialético, para a construção de conceitos de biologia. Ciência \& educação. (Bauru) [online], v. 18, n. 2, p. 335-352, 2012.

OLIVEIRA, M. M. Como fazer pesquisa qualitativa. 2. ed. Petrópolis: Vozes, 2008. 
PARKER, R. Estigma, preconceito e discriminação na saúde pública global. Cad Saúde Pública, v. 28, n. 1, p. 164-9, 2012.

PEREIRA, M. O.; VARGAS, D.; OLIVEIRA, M. A. F. Reflexão acerca da política do Ministério da Saúde brasileiro para a atenção aos clientes de álcool e outras drogas sob a óptica da sociologia das ausências e das emergências. Rev. Eletrônica Saúde Mental Álcool e Drogas, São Paulo, v. 8, n. 1, p. 9-16, 2012.

SCHILLING, F.; MIYASHIRO, S. G. Como incluir? O debate sobre o preconceito e o estigma na atualidade. Educ Pequi, São Paulo, v. 34, n. 2, p .243-54, 2008.

WETZEL, C. Avaliação de cuidados de saúde mental: a construção de um processo participativo. 2005. Tese (Doutorado em Enfermagem) - Escola de Enfermagem de Ribeirão Preto, Universidade de São Paulo, Ribeirão Preto, 2005.

WEISS, M. G. et al. Cultural epidemiology of TB with reference to gender in Bangladesh, India and Malawi. Int J Tuberc Lung Dis, n. 12, v. 7, p. 837-847, 2008.

WORLD HEALTH ORGANIZATION. Global Tuberculosis Report 2017. Geneva: WHO, 2017.

\section{Nota}

${ }^{1}$ T. S. Fernandes e M. K. Q. Garcia analisaram os dados e elaboraram o artigo. N. S. Pedrosa interpretou os dados e elaborou o artigo. A. M. B. F. da Silva foi responsável pelo projeto, planejamento e elaboraçáo do artigo. 


\section{Abstract}

Stigma and prejudice today: the experience of tuberculosis patients in occupational therapy workshops

Objective: To qualitatively assess the stigma and prejudice experienced by tuberculosis patients in their professional socio-affective context, their relationships and subjectivities. Method: Evaluative-qualitative study, developed through the Fourth Generation Evaluation, conducted with two interest groups (18 clients and 11 family members) served by the Unified Health System of the West Zone of Rio de Janeiro. For data collection, observation, individual interviews and occupational therapy host groups were used; the analysis was carried out using the hermeneutic-dialectic-comparative method. Results: The evaluation process showed that society perceives tuberculosis patients from their virtual image, disregarding their real image, that is, the stigmatizing identity predominates, generating the idea of non-citizens, without the right to a social place, work, that they must be excluded, their uniqueness abolished, potentiating situations of vulnerability, being taxed as those that do not fit the ideals of society. Conclusion: It is necessary to demystify the social imaginary that excludes tuberculosis patients, and the development of public policies with health education, prevention, information and fight against stigma is pertinent.

Keywords: tuberculosis; qualitative research; occupational therapy; social vulnerability. 